\title{
Metabolic Alteration of Trypanosoma cruzi during Differentiation of Epimastigote to Trypomastigote Forms
}

\author{
Salvatore G. De-Simone ${ }^{1,2,3, *}$, Saulo C. Bourguignon ${ }^{3}\left(\mathbb{D}\right.$, Priscila S. Gonçalves ${ }^{1,3}$, Guilherme C. Lechuga ${ }^{1,2}(\mathbb{D}$ \\ and David W. Provance, Jr. ${ }^{1,2}$
}

check for

updates

Citation: De-Simone, S.G.

Bourguignon, S.C.; Gonçalves, P.S.;

Lechuga, G.C.; Provance, D.W., Jr.

Metabolic Alteration of Trypanosoma

cruzi during Differentiation of

Epimastigote to Trypomastigote

Forms. Pathogens 2022, 11, 268.

https://doi.org/10.3390/

pathogens 11020268

Academic Editors: Guan Zhu and Bang Shen

Received: 19 December 2021

Accepted: 14 February 2022

Published: 19 February 2022

Publisher's Note: MDPI stays neutral with regard to jurisdictional claims in published maps and institutional affiliations.

Copyright: (C) 2022 by the authors. Licensee MDPI, Basel, Switzerland. This article is an open access article distributed under the terms and conditions of the Creative Commons Attribution (CC BY) license (https:// creativecommons.org/licenses/by/ $4.0 /)$
1 Center for Technological Development in Health (CDTS), FIOCRUZ, National Institute of Science and Technology for Innovation in Neglected Populations Diseases (INCT-IDPN), Rio de Janeiro 21040-900, RJ, Brazil; priscilla.desimone@cdts.fiocruz.br (P.S.G.); guilherme.lechuga@cdts.fiocruz.br (G.C.L.); bill.provance@cdts.fiocruz.br (D.W.P.J.)

2 Epidemiology and Molecular Systematic Laboratory, Oswaldo Cruz Institute, FIOCRUZ, Rio de Janeiro 21040-900, RJ, Brazil

3 Cellular and Molecular Biology Department, Biology Institute, Federal Fluminense University, Niterói 24020-141, RJ, Brazil; saulocb@id.uff.br

* Correspondence: salvatore.simone@fiocruz.br

\begin{abstract}
Intracellular parasites such as Trypanosoma cruzi need to acquire valuable carbon sources from the host cell to replicate. Here, we investigated the energetic metabolism of T. cruzi during metacyclogenesis through the determination of enzymatic activities and quantification by HPLC of glycolytic and Krebs cycle short-chain carboxylic acids. Altered concentrations in pyruvate, acetate, succinate, and glycerate were measured during the growth of epimastigote in the complex medium $\mathrm{BHI}$ and their differentiation to trypomastigotes in the chemically defined medium, TAU3AAG. These alterations should represent significant differential metabolic modifications utilized by either form to generate energy. This paper is the first work dealing with the intracellular organic acid concentration measurement in T. cruzi parasites. Although it confirms the previous assumption of the importance of carbohydrate metabolism, it yields an essential improvement in T. cruzi metabolism knowledge.
\end{abstract}

Keywords: Trypanosoma cruzi; carbohydrate metabolism; organic acid; high-performance liquid chromatography; carboxylic acid; enzyme activity

\section{Introduction}

Trypanosoma cruzi, the etiological agent of Chagas disease, presents during its life cycle three primary morphologically and physiologically distinct evolutive forms designated as epimastigote, trypomastigote, and amastigote [1]. As the epimastigote (epi) forms are non-infective, a critical step in the lifecycle of $T$. cruzi is its transformation into the highly infective metacyclic trypomastigote (trypo) forms. This process, designated as metacyclogenesis, can be reproduced in vitro using several specific growth conditions [2-4], including a chemically defined medium $[5,6]$. Besides the transformations of epimastigotes, other ways of metacyclogenesis also occur in the vector $[7,8]$.

It is known that the metacyclogenesis of these parasites leads to some morphological $[9,10]$ and biochemical changes that include alterations in the surface carbohydrates [11], variations in the lipid composition [12,13], and fatty acids [14]. Previous studies have reported that both the epimastigote and trypomastigote forms can obtain energy from glucose, amino acids, fatty acids, and glycerol metabolism [15-20]. Yet, despite the various metabolic studies on T. cruzi, the principal substrate for energy generation during differentiation is a controversial topic. Organic acids have been suggested as the primary substrate for energy generation in trypomastigote $[15,21]$. On the other hand, glucose, rather than amino acids, has been indicated as the principal substrate in epimastigotes. It has also been postulated that this parasite oxides amino acids to generate ATP [22,23]. 
Although the basic knowledge about trypanosomatid carbohydrate metabolism and its particularities has been unraveled in the previous decades [24,25], new information has become available in recent years, showing that the process is more elaborate and has additional information on peculiar features [13,26-28]. These features have been evaluated through enzymatic measurements [16,29,30], enzyme expression studies [16,28-30], predictions through computational approaches [31], gene expression/genomic analyses [32-34], and metabolomics [26,35].

The use of high-performance liquid chromatography (HPLC) to analyze organic acids in biomedical and pharmacological applications [36-38] has opened the possibility of investigating their concentrations as the final products of diverse enzymatic activities under different cellular growth conditions. In the present work, we focused our attention on determining the short-chain carboxylic acids produced from glycolysis and Krebs cycle intermediates by ion-exchange high-performance liquid chromatography during the metacyclogenesis of T. cruzi parasites. Furthermore, these organic acid concentrations were compared to parasites grown under different culturing conditions.

\section{Results}

\subsection{Organic Acids}

Separate organic acid analyses were performed in populations of parasites grown in a brain heath infusion (BHI) complex and TAU3AAG chemically defined media. Samples of parasites cultured in BHI medium were harvested in the logarithmic phase at 24, 72, and $120 \mathrm{~h}$ and in the stationary phase at $168 \mathrm{~h}$ to follow the organic acid profile during the transition. The organic acid profile was monitored during the differentiation process using samples withdrawn at 24, 48, and $72 \mathrm{~h}$ of culture in TAU3AAG medium. At $24 \mathrm{~h}$, the parasite population consisted of about $75 \%$ epimastigotes and $25 \%$ trypomastigotes forms. Differentiation reached nearly $50 \%$ at $48 \mathrm{~h}$, and by $72 \mathrm{~h}$, the parasite population consisted mainly of the trypomastigote form (70\%). The harvested parasite samples were processed for high-performance liquid chromatography (HPLC) analysis, as described in the materials and methods section, to identify the organic acids extracted by comparing retention times to standards. The organic acid concentrations were obtained by integrating the chromatographic peak area with means. Figure 1 graphically represents the concentration variations of these acids extracted from BHI parasites, and Figure 2 for those extracted from TAU3AAG parasites (Figures S1 and S2).

Tables S1 and S2 show the concentrations of parasite-derived organic acids cultured in $\mathrm{BHI}$ and TAU3AAG medium, respectively.

The G2P concentration obtained from parasites cultured in BHI media was maintained high in the various time points studied, with a slight decrease from 120 to $168 \mathrm{~h}$. The citrate, acetate, and malate presented a similar profile: a significant increase in concentration from 24 to $120 \mathrm{~h}$, with a fall at $168 \mathrm{~h}$, adequate only for acetate and succinate. Pyruvate, malate, and succinate concentrations remained low, but a significant increase in pyruvate concentration was observed from 120 to $168 \mathrm{~h}$. On the other hand, malate concentration decreased after $72 \mathrm{~h}$ and remained stable at the lowest levels (Figure 1).

During metacyclogenesis in TAU3AAG media, the intermediate acids involved in the glycolytic pathway (glycerate-2-phosphate (G2P) and pyruvate) decreased, as well as the acetate that presented a one- to twofold decrease in concentration (Figure 2). Despite this decrease, however, the attention of the G2P remained high compared to the other acids. Succinate was the only acid that increased concentration (four- to fivefold) from 24 to $48 \mathrm{~h}$, but the whole time at low concentrations along with the culture (Figure 2; Table S2). 


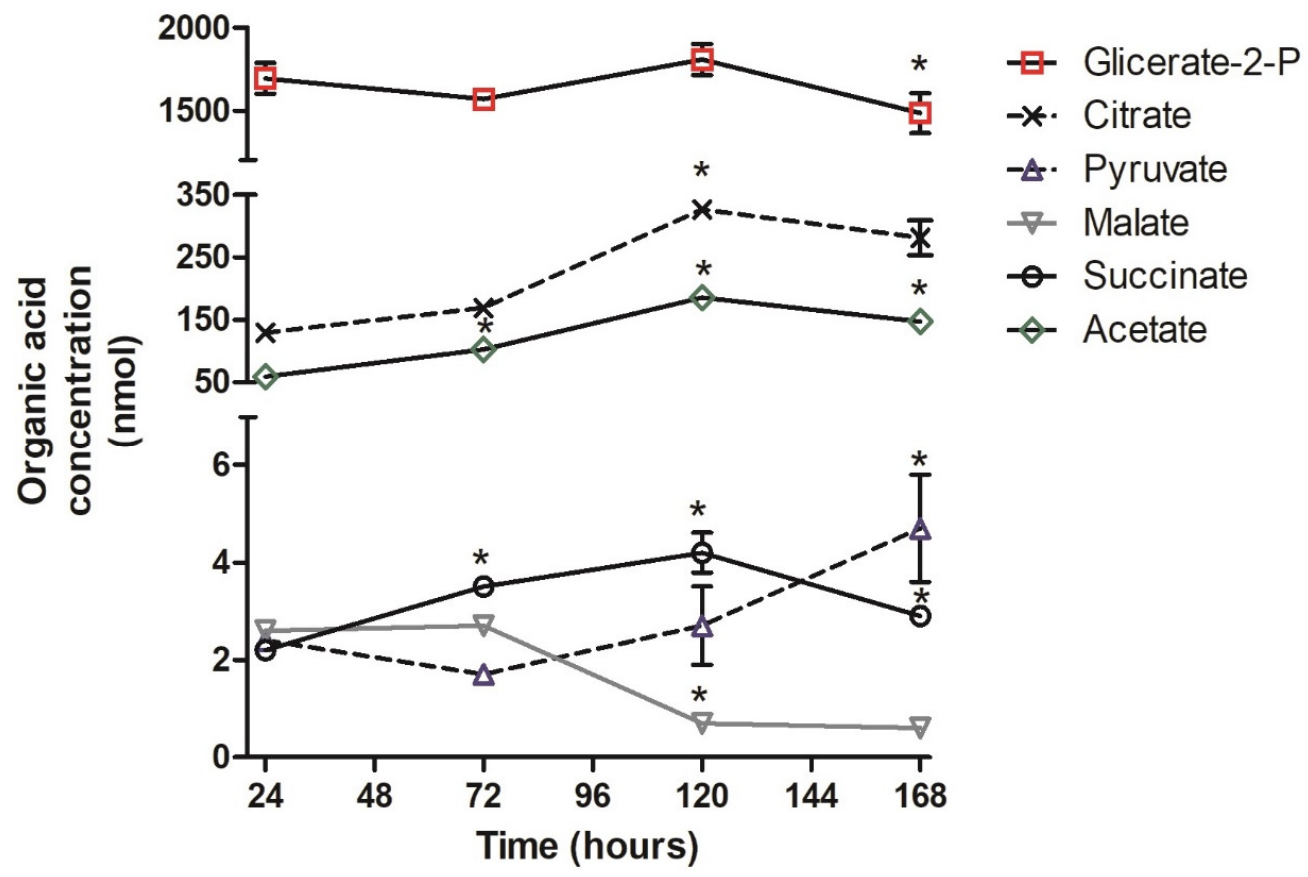

Figure 1. Concentration of parasites' organic acids after different growth periods as a function of growth time in $\mathrm{BHI}$ media. The concentrations of succinate $(-\mathrm{O}-)$, malate $(-\nabla-)$, and pyruvate $(-\Delta-)$ were nearly equivalent and appeared superimposed, while citrate $(-X-)$ and acetate $(-\diamond-)$ show similar profiles during cultivation. However, the glycerate $2 p(-\square-)$ concentration was noticeably higher than the others were. Values correspond to the mean \pm SD (three biological replicates) of organic acid concentration measured in three independent cultures from a sample size of $3 \times 10^{8}$ parasites. ${ }^{*}: p \leq 0.05$, statistically significant from previous time point.

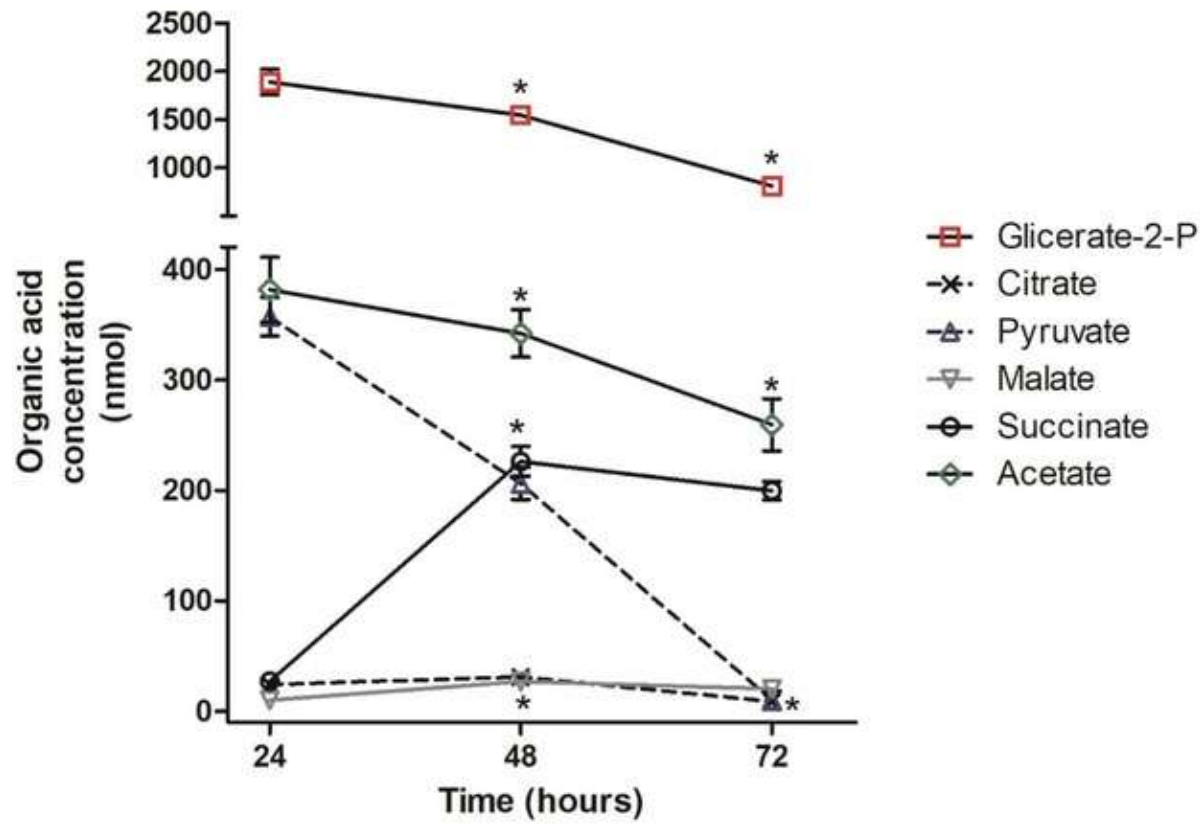

Figure 2. Concentration of the organic acid from parasites in different times of the cultivation in TAU3AAG medium: glycerate $2 p(-\square-)$, citrate $(-X-)$, pyruvate $(-\Delta-)$, malate $(-\nabla-)$, acetate $(-\diamond-)$ and succinate $(-\mathrm{O}-)$. The values correspond to the mean \pm S.D (three biological replicates) of the concentration in nmoles of organic acid of three experiments determined in a population of $3 \times 10^{8}$ parasites. ${ }^{*}: p \leq 0.05$, statistically significant from previous time point. 


\subsection{Enzymatic Activities}

At different differentiation times under TAU3AAG or BHI media, samples of parasites were collected and extracted as described to evaluate the enzymatic activity of the aldolase, pyruvate kinase, and hexokinase. The results are shown in Figures 3 and 4 and Tables S3 and S4. Pk and Ald activity decreased significantly after $24 \mathrm{~h}$ and after $48 \mathrm{~h}$ for Hk. After $72 \mathrm{~h}$, a small but significant increase in $\mathrm{Pk}$ and Hk activity was observed.

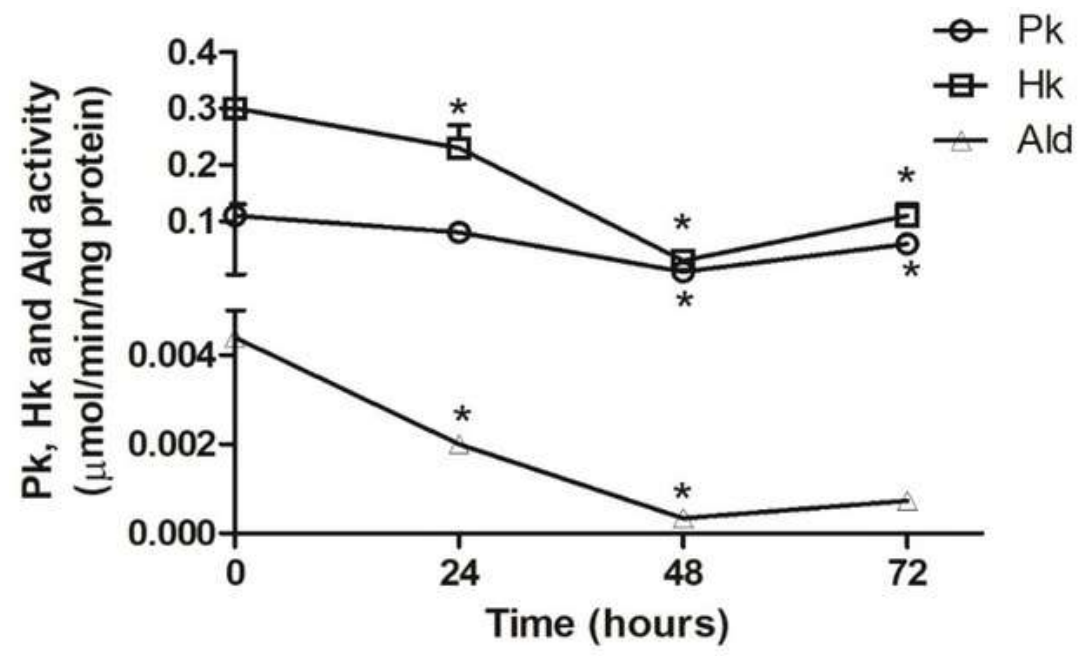

Figure 3. Specific enzymatic activity of pyruvate kinase (Pk), hexokinase (Hk), and aldolase (Ald) in T. cruzi during its differentiation to trypomastigotes in TAU3AAG medium. The percentage of trypomastigotes forms were $<1 \%, 25 \%, 50 \%$, and $70 \%$ at $0,24,48$, and $72 \mathrm{~h}$, respectively. ${ }^{*}: p \leq 0.05$, statistically significant from previous time point.

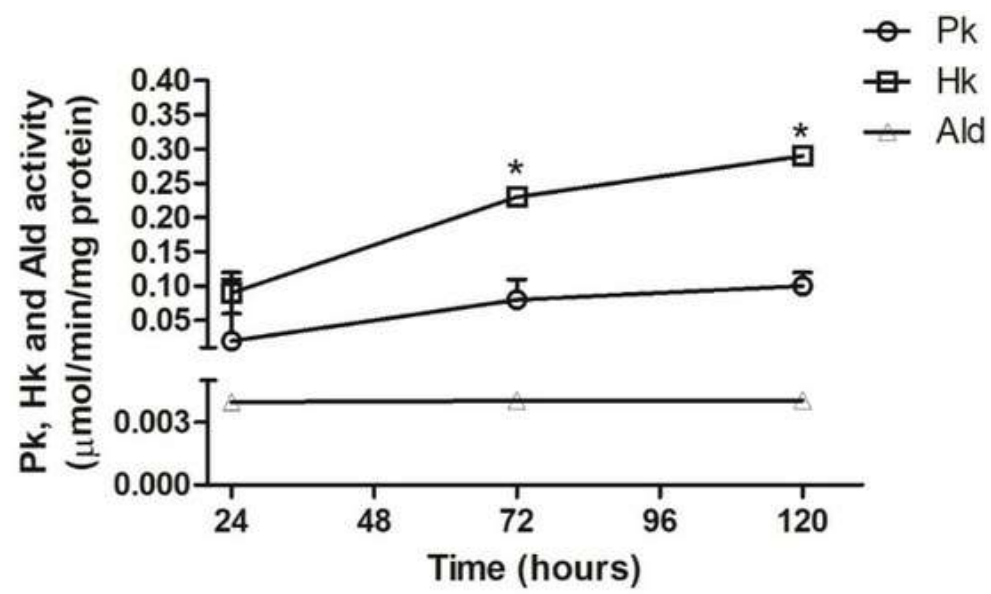

Figure 4. Activity of pyruvate kinase ( $\mathrm{Pk})$, hexokinase (Hk), and aldolase (Ald) in T. cruzi cultured in $\mathrm{BHI}$ medium for different times. Extracts from $2 \times 10^{8}$ parasites were assayed in three independent experiments, and the values plotted correspond to the average. The unit for Pk and Hk was $\mu$ moles subst $/ \mathrm{min} / \mathrm{mg}$ protein, and for the aldolase nmoles subst $/ \mathrm{min} / \mathrm{mg}$ protein and means an S.D. are presented. *: $p \leq 0.05$, statistically significant from previous time point.

In the total extract from epimastigotes cultured in BHI media (Figure 4), the aldolase activity remained constant and appeared enhanced in the lag and log phases (24-72 h) as well as at the beginning of the stationary phase $(120 \mathrm{~h})$. On the other hand, the enzymatic activity of pyruvate kinase and hexokinase at $120 \mathrm{~h}$ of culture in BHI media increased four- to fivefold and threefold from $24 \mathrm{~h}$, respectively. Comparing the profiles of enzyme activity in the extracts of parasites maintained in TAU3AAG (Figure 3), and cultured in BHI media (Figure 4), the activity of three enzymes (PK, HK, and Ald) in the glycolytic 
pathway dropped during the first $24 \mathrm{~h}$ of differentiation. However, there is no significant difference (Tables S3 and S4) in the pyruvate kinase activity in epimastigotes between $24 \mathrm{~h}$, $72 \mathrm{~h}$, and $120 \mathrm{~h}$.

\section{Discussion}

Several studies have been performed on the energetic metabolism in trypanosomatids by evaluating enzymatic activities or through computational approaches. Yet, few have quantified the intermediate metabolic products of the different enzymatic reactions as a means to investigate differences between organisms or their stages of development. Here, an HPLC analysis of short-chain carboxylic acid from glycolytic and Krebs cycle of $T$. cruzi showed differences in the concentration of various compounds during its growth in BHI medium (Figure 1) and its differentiation in TAU3AAG medium (Figure 2). These differences indicate that both energetic pathways are modulated and most likely reflect the dramatic changes in the physiological state of the parasite $[26,39,40]$.

At the end of the differentiation process (72 $\mathrm{h}$ in TAU3AAG medium), the high amounts of G2P and the low level of pyruvic acid (Figure 2) suggest that these values could be the consequence of the allosteric regulation of the glycolytic pathway. In trypanosomatids, the glycolytic pathway is not regulated similarly to the classical control points of hexokinase and phosphofructokinase of bacteria and mammalian cells. Instead, pyruvate kinase is the subject of solid allosteric regulation $[15,24,39]$. The low enzymatic activity of pyruvate kinase (Figure 3) and the pyruvate concentration agree with this regulation point. Therefore, if the glycolytic pathway operates at a basal level at any given moment, it can be supposed that it utilizes another path(s) to generate ATP.

One hypothesis is that during differentiation in the TAU3AAG medium, proteins from reservosomes organelles [41] can be used to generate ATP. However, Figueiredo et al. [42] showed that the endogenous energy reserve, present in epimastigote and trypomastigote forms, is not a glycogen-like polysaccharide but is represented by lipids and protein, respectively. Still, during the aging of a T. cruzi culture, type I reservosomes contain an electron-dense matrix with lipids, and type II reservosomes present a homogeneous matrix without lipid inclusion but with the presence of proteins [19,43,44]. Furthermore, these organelles were absent in highly infective bloodstream trypomastigote forms isolated from infected mice [43]. Therefore, these results indicated a significant difference in metabolic reserves within these different evolutive forms of trypanosomatids [41,45,46].

The decrease in enzymatic activity of aldolase, pyruvate kinase, and hexokinase (Figures 3 and 4) that associated with the reduction in the levels of G2P and pyruvate (Figure 2), found in our study indicates that during metacyclogenesis or morphological change of the parasite, the glycolytic pathway or glucose consumption is reduced.

These results follow the data described by Adroher et al. 1990 [16]. These authors compared the enzymatic activity of three enzymes (hexokinase, phosphofructokinase, and pyruvate kinase) in epimastigotes and metacyclic of T. cruzi. Higher activity of the two first enzymes was found in epimastigotes and metacyclic, whereas pyruvate kinase had similar activity in both forms of the parasite. The specific activity is an important parameter and demonstrated clearly that in this work, a quantitative change in the glycolytic pathway of both culture forms of T. cruzi. Furthermore, a similar observation with the decreasing glycolytic enzymatic activity was obtained during amastigote differentiation to epimastigote forms $[16,45]$.

Likewise, Barisón et al. [34] used metabolomics to access the levels of 47 metabolites both in the exponential and stationary phases of T. cruzi epimastigotes observed that there was also a reduction in the levels of citrate, pyruvate, malate when parasites in the stationary phase were compared to parasites in the exponential phase.

Therefore, it appears that this metabolic change is a general process that precedes the differentiation processes of amastigote to epimastigote, epimastigote to trypomastigote, and possibly trypomastigote to amastigote. However, this presumably does not reflect the 
natural changes in the rectum of the vector, the leading site of metacyclogenesis, since the presence of glucose is questionable [46].

Conversely, little is known about the possibilities of using externally available and internally stored fatty acids as resources to survive in nutrient-poor environments and to sustain metacyclogenesis. For example, studies conducted with a parasite population consisting of $99 \%$ in the epimastigote form showed that the conversion of palmitic acid into $\mathrm{CO} 2$ was minimum, which indicated that the use of this fatty acid is irrelevant in this life stage [21]. However, the same authors showed that the conversion of palmitic acid into $\mathrm{CO} 2$ increased in proportion to the appearance of the trypomastigote form, thus suggesting the usage of lipid reserves [21,47].

The endogenous energy reserve present in various evolutive forms of T. cruzi has been attributed to carbohydrates [19]. However, while epimastigotes can interchange glucose and amino acids, they also can accumulate fatty acids into lipid droplets during growth and use this reserve to support its growth after glucose exhaustion [13,48,49]. Furthermore, this same study demonstrated that the insect stages coordinate the activation of fatty acid consumption with the metabolism of glucose [48].

Maintaining a high enzymatic activity in the glycolytic pathway during the culture of epimastigote forms in the BHI medium (Figure 4) indicates that the primary energy source in this form should be carbohydrates. These findings confirm a previous result [20], although the low activity of glycolytic enzymes and intermediates, along with differentiation, suggests that glycolysis is not the primary pathway used during metacyclogenesis. This followed another study conducted that measured the metabolites produced and excreted during culture conditions with proton nuclear magnetic resonance spectroscopy [20]. The final products of glucose catabolism differed quantitatively and qualitatively for the three lifecycle stages of T. cruzi. To a lesser extent, the end products of metabolism produced by epimastigote forms were mainly acetate and pyruvate and L-alanine and ethanol. Differences between epimastigotes and metacyclic forms were only quantitative. However, accessible amastigotes and amastigote-like forms excreted acetate, glycerol, pyruvate, and to lesser extent succinate, but no L-alanine or ethanol [18].

Thus, the association of both results with the disappearance of the lipids in the reservosomes [26] suggests whether or not epimastigotes use monosaccharides in the vector and oxidize through beta-oxidation before the end of metacyclogenesis. These organelles are absent in amastigotes and trypomastigotes, being exclusive to epimastigotes of T. cruzi [42-44]. However, despite this strong evidence, additional studies are needed to demonstrate that beta-oxidation is activated in the differentiation process or if it participates together with the oxidation of the amino acids [13,24].

The oscillations in the concentration of the intermediates from the Krebs cycle (malate and succinate) demonstrate that the metabolic alterations during differentiation can also affect the main oxidative pathway in T. cruzi [50-53].

\section{Materials and Methods}

\subsection{Parasites and Growth Condition}

The Dm28c clone of Trypanosoma cruzi was maintained as previously described [17] and harvested epimastigote forms after growth in BHI medium for 1,3,5, and 7 days. For metacyclogenesis, epimastigotes harvested by centrifugation from a five-day culture in $\mathrm{BHI}$ were washed and incubated at room temperature for $2 \mathrm{~h}$ in a solution of triatomine artificial urine (TAU; $190 \mathrm{mM} \mathrm{NaCl}, 17 \mathrm{mM} \mathrm{KCl}, 2 \mathrm{mM} \mathrm{MgCl} 2,2 \mathrm{mM} \mathrm{CaCl}_{2}, 0.035 \%$ sodium bicarbonate, $8 \mathrm{mM}$ phosphate, $\mathrm{pH}$ 6.8) and three days at $28^{\circ} \mathrm{C}$ in TAU3AAG (TAU containing $10 \mathrm{mM}$ L-proline, $50 \mathrm{mM}$ sodium L-glutamate, $2 \mathrm{mM}$ sodium L-aspartate, and $10 \mathrm{mM}$ glucose) at a density of $5 \times 10^{6}$ cells $/ \mathrm{mL}$.

\subsection{Extraction of Organic Acids}

Parasites were washed twice by centrifugation in PBS before loading into a screwcapped culture tube fitted with a Teflon-line cap. An extraction reagent $(200 \mu \mathrm{L}$ of $18 \mathrm{~N}$ 
$\mathrm{H}_{2} \mathrm{SO}_{4}, 0.6 \mathrm{~g}$ of $\mathrm{NaCl}, 5 \mathrm{~mL}$ of diethyl ether, and $25 \mu \mathrm{L}$ of acetonitrile) was added and blended on a vortex mixer for $1 \mathrm{~min}$ before centrifugation $(1000 \times g$ for $1 \mathrm{~min})$. The ether phase added $0.2 \mathrm{~mL}$ of $0.1 \mathrm{~N} \mathrm{NaOH}$, and the tubes were gently shaken. The lower $\mathrm{NaOH}$ phase was tested with a $\mathrm{pH}$ paper, and $0.1 \mathrm{~N} \mathrm{NaOH}$ was added, one drop at a time, to obtain a $\mathrm{pH}$ of 9.0. Next, the tubes were vortexed for $1 \mathrm{~min}$, centrifuged as before, and removed and discarded the ether phase. Twenty-five microliters of acetonitrile were added, and the tubes were left uncapped for about $5 \mathrm{~min}$ to allow the residual ether to evaporate.

\subsection{HPLC Analysis}

Samples of $80 \mu \mathrm{L}$ were injected into a cation exchange HPLC column (Aminex HPX$87 \mathrm{H}, 300 \times 7.8 \mathrm{~mm}$, ID, Bio-Rad Laboratories Inc. São Paulo, Brazil) previously equilibrated with $0.007 \mathrm{~N} \mathrm{H}_{2} \mathrm{SO}_{4}$. The organic acids were fractionated for $60 \mathrm{~min}$ at $35^{\circ} \mathrm{C}$ on an automatic HPLC system (6A model; Schimadzu, Kyoto, Japan) at a flow rate of $0.6 \mathrm{~mL} \mathrm{~min}^{-1}$ using a full-scale unit absorbance of 0.08 wavelength of $210 \mathrm{~nm}$. The column was calibrated in the same solution with a standard organic acid mixture (citrate, tartrate, malate, succinate, and acetate) purchased from Bio-Rad Laboratories Inc. (São Paulo, Brazil) to determine the relative concentration. Other organic acids (glycerate-2-phosphate and pyruvate) were dissolved in $0.07 \mathrm{~N} \mathrm{H} 2 \mathrm{O} 4$ to prepare solution stocks. Quantity was determined using standards of organic acid concentration to calibrate the data module for the units processed by the system integrator. Values of the analysis correspond to the mean $\pm \mathrm{SD}$ of three biological replicates.

\subsection{Enzymatic Assay and Protein Estimation}

Hexokinase and pyruvate kinase enzymes were assayed at $25{ }^{\circ} \mathrm{C}$ in a final volume of $1 \mathrm{~mL}$, and changes were measured in absorbance at $340 \mathrm{~nm}$ for $5 \mathrm{~min}$ and measured and expressed as specific activities ( $\mu \mathrm{mol} \cdot \mathrm{min}^{-1} \cdot \mathrm{mg}^{-1}$ of protein) as described [16]. In addition, aldolase activity was measured by a colorimetric assay kit (MAK223, SigmaMerck, St. Louis, MO, USA) and protein concentration using a colorimetric assay based on the Bradford method (Bio-Rad Laboratories Inc., São Paulo, Brazil).

\subsection{Statistical Analysis}

Statistical analyses were performed on GraphPad Prism version 5.03 (GraphPad Software, San Diego, CA, USA) using a one-way ANOVA test and Bonferroni post-test to compare results, and data were considered statistically different when $p \leq 0.05$.

\section{Conclusions}

We performed a qualitative and quantitative analysis of organic acids during the growth and differentiation of T. cruzi. The variation in oxaloacetate detection performed in this study compared to other studies using a different Trypanosomatidae was $\geq 2 \%$ [17]. Comparative studies of oxaloacetate and enzymatic activity confirmed that glucose is the primary energy source of epimastigote forms in a glucose medium. The Krebs cycle was functional in the oxidative succinate-oxaloacetate direction. A decrease in the utilization of the glycolytic pathway occurred, despite the high concentration of glucose in the extracellular medium during the differentiation of epimastigote to trypomastigote forms in TAU3AAG medium. This fact was confirmed by the reduction in glycerate-2-phosphate and pyruvate concentration and the decrease in the activity of the enzymes hexokinase, aldolase, and pyruvate kinase. These findings suggest that other energy factors such as lipids and proteins can be used during differentiation.

Supplementary Materials: The following are available online at https:/ /www.mdpi.com/article/10 $.3390 /$ pathogens11020268/s1. Figure S1: Overlapping the total chromatographic profiles of organic acids extracted from parasites at different times $(0,24,48$, and $72 \mathrm{~h})$ during cultivation on TAU3AAG medium, performed using the CR10 chromatographic program (Schimadzu, Kyoto, Japan). The extraction of organic acids was carried out as described in $\mathrm{MM}$, and the separation was carried out on an Aminex XPX-87H column at a flow of $0.6 \mathrm{~mL} / \mathrm{min}$, using $0.07 \mathrm{mM} \mathrm{H}_{2} \mathrm{SO}_{4}$ as eluent. Detection 
was performed at $210 \mathrm{~nm}$ and a sensitivity of 0.08 AUFS. The arrows indicate the unidentified acids systematically located throughout the cultivation at the BHI medium (Figure 4). Figure S2. Analysis of organic acids on an Aminex XPX-87H column extracted from parasites at different times cultivated in BHI: A (24 h), B (72 h), C (120 h), D (168 h), E (overlapping). Table S1: Concentration of organic acids in different times of the differentiation of the Trypanosoma cruzi in TAU3AAG medium, obtained through the Aminex HPX 87H column. Table S2: Concentration of the acids organic during the growth of the Trypanosoma cruzi in BHI medium, obtained through the Aminex HPX 87H column. Table S3: Correlation between the percentage of epimastigote and trypomastigote forms and the specific enzymatic activity of aldolase (Ald), hexokinase (Hk), and pyruvate kinase (Pk) enzymes during the differentiation of the T. cruzi in TAU3AAG medium. Table S4: Specific enzymatic activity of the aldolase (Ald), hexokinase (Hk), and pyruvate kinase (Pk) extracted from epimastigotes maintained in BHI medium.

Author Contributions: Conceptualization, S.G.D.-S.; validation, S.C.B.; formal analysis, S.C.B., S.G.D.-S.; investigation, S.C.B., G.C.L. and P.S.G.; resources, S.G.D.-S.; data curation, S.C.B.; writingoriginal draft preparation, S.G.D.-S; writing—review and editing, S.G.D.-S.; visualization, D.W.P.J.; supervision, S.G.D.-S.; project administration, S.G.D.-S.; funding acquisition, S.G.D.-S. All authors have read and agreed to the published version of the manuscript.

Funding: S.G.S. received support from the Brazilian Council for Scientific Research (CNPq \# 467.488.2014-2; \#3075732011; \#3013322015-0) and Carlos Chagas Filho Foundation for Research Support of the State of Rio de Janeiro (FAPERJ \# 110.198-13; \# 202.841-2018).

Institutional Review Board Statement: This information is contained in the review board statement. Informed Consent Statement: Not applicable.

Data Availability Statement: The data presented in this study are available on request from the corresponding author.

Acknowledgments: G.C.L. is a postdoctoral fellow from the Brazilian Council for Scientific Research $(\mathrm{CNPq})$, and P.S.G. is a DSci student from the Post-Graduation Program in Science and Biotechnology from the Federal Fluminense University.

Conflicts of Interest: The authors declare no conflict of interest. The funders had no role in the study's design; in the collection, analyses, or interpretation of data; in the writing of the manuscript; or in the decision to publish the results.

\section{References}

1. Tyler, K.M.; Engman, D.M. The life cycle of Trypanosoma cruzi revisited. Int. J. Parasitol. 2001, 31, 472-481. [CrossRef]

2. Contreras, V.T.; Morel, C.M.; Goldenberg, S. Stage-specific gene expression precedes morphological changes during Trypanosoma cruzi metacyclogenesis. Mol. Biochem. Parasitol. 1985, 14, 83-96. [CrossRef]

3. Krassner, S.M.; Granger, B.; Phermsangngnam, P.; Le, T.; Linden, V. Further studies on substrates inducing metacyclogenesis in Trypanosoma cruzi. J. Protozool. 1990, 37, 128-132. [CrossRef]

4. Parodi-Talice, A.; Monteiro-Goes, V.; Arrambide, N.; Avila, A.R.; Duran, R.; Correa, A.; Dallagiovanna, B.; Cayota, A.; Krieger, M.; Goldenberg, S.; et al. Proteomic analysis of metacyclic trypomastigotes undergoing Trypanosoma cruzi metacyclogenesis. J. Mass Spectrom. 2007, 42, 1422-1432. [CrossRef] [PubMed]

5. Contreras, V.T.; Salles, J.M.; Thomas, N.; Morel, C.M.; Goldenberg, S. In vitro differentiation of Trypanosoma cruzi under chemically defined conditions. Mol. Biochem. Parasitol. 1985, 16, 315-327. [CrossRef]

6. Isola, E.L.; Lammel, E.M.; Redruello, M. Trypanosoma cruzi: Conditions required to improve metacyclic differentiation in axenic culture. Rev. Argent. Microbiol. 1989, 21, 9-14. [PubMed]

7. Schaub, G.A. Trypanosoma cruzi: Quantitative studies of development of two strains in small intestine and rectum of the vector Triatoma infestans. Exp. Parasitol. 1989, 68, 260-273. [CrossRef]

8. De Lima, A.R.; Navarro, M.C.; Arteaga, R.Y.; Contreras, V.T. Cultivation of Trypanosoma cruzi epimastigotes in low glucose axenic media shifts its competence to differentiate at metacyclic trypomastigotes. Exp. Parasitol. 2008, 119, 336-342. [CrossRef]

9. Hamedi, A.; Botelho, L.; Britto, C.; Fragoso, S.P.; Umaki, A.C.; Goldenberg, S.; Bottu, G.; Salmon, D. In vitro metacyclogenesis of Trypanosoma cruzi induced by starvation correlates with a transient adenylyl cyclase stimulation as well as with a constitutive upregulation of adenylyl cyclase expression. Mol. Biochem. Parasitol. 2015, 200, 9-18. [CrossRef]

10. Schaub, G.A.; Lösch, P. Trypanosoma cruzi: Origin of metacyclic trypomastigotes in the urine of the vector Triatoma infestans. Exp. Parasitol. 1988, 65, 174-186. [CrossRef] 
11. de Andrade, A.F.; Esteves, M.J.; Angluster, J.; Gonzales-Perdomo, M.; Goldenberg, S. Changes in cell-surface carbohydrates of Trypanosoma cruzi during metacyclogenesis under chemically defined conditions. J. Gen. Microbiol. 1991, 137, $2845-2849$. [CrossRef] [PubMed]

12. Kaneda, Y.; Nagakura, K.; Goutsu, T. Lipid composition of three morphological stages of Trypanosoma cruzi. Comp. Biochem. Physiol. B 1986, 83, 533-536. [CrossRef]

13. Booth, L.A.; Smith, T.K. Lipid metabolism in Trypanosoma cruzi: A review. Mol. Biochem. Parasitol. 2020, 240, 111324. [CrossRef]

14. Esteves, M.G.; Gonzales-Perdomo, M.; Alviano, C.S.; Angluster, J.; Goldenberg, S. Changes in fatty acid composition associated with differentiation of Trypanosoma cruzi. FEMS Microbiol. Lett. 1989, 50, 31-34. [CrossRef] [PubMed]

15. Cazzulo, J.J.; Franke de Cazzulo, B.M.; Engel, J.C.; Cannata, J.J. End products and enzyme levels of aerobic glucose fermentation in trypanosomatids. Mol. Biochem. Parasitol. 1985, 16, 329-343. [CrossRef]

16. Adroher, F.J.; Osuna, A.; Lupianez, J.A. Differential energetic metabolism during Trypanosoma cruzi differentiation. II Hexokinase, phosphofructokinase, and pyruvate kinase. Mol. Cell. Biochem. 1990, 94, 71-82. [CrossRef] [PubMed]

17. Durieux, P.O.; Schutz, P.; Brun, R.; Kohler, P. Alterations in Krebs cycle enzyme activities and carbohydrate catabolism in two strains of Trypanosoma brucei during in differentiation of their bloodstream to procyclic stages. Mol. Biochem. Parasitol. 1991, 45, 19-28. [CrossRef]

18. Cazzulo, J.J. Intermediate metabolism in Trypanosoma cruzi. J. Bioenerg. Biomembr. 1994, 26, 157-165. [CrossRef]

19. Maugeri, D.A.; Cannata, J.J.; Cazzulo, J.J. Glucose metabolism in Trypanosoma cruzi. Essays Biochem. 2011, 51, 15-30. [CrossRef]

20. Sanchez-Moreno, M.; Fernandez-Becerra, M.C.; Castilla-Calvente, J.J.; Osuna, A. Metabolic studies by ${ }^{1} \mathrm{H}$ NMR of different forms of Trypanosoma cruzi as obtained by 'in vitro' culture. FEMS Microbiol. Lett. 1995, 33, 119-125. [CrossRef]

21. Wood, E.D. Trypanosoma cruzi: Organic acid metabolism in vitro. Exp. Parasitol. 1975, 37, 60-66. [CrossRef]

22. Silber, A.M.; Colli, W.; Ulrich, H.; Alves, M.J.; Pereira, C.A. Amino acid metabolic routes in Trypanosoma cruzi: Possible therapeutic targets against Chagas' disease. Curr. Drug Targets Infect. Disord. 2005, 5, 53-64. [CrossRef]

23. Manchola, N.C.; Rapado, L.N.; Barisón, M.J.; Silber, A.M.J. Biochemical characterization of branched-chain amino acids uptake in Trypanosoma cruzi. J. Eukaryot. Microbiol. 2016, 63, 299-308. [CrossRef]

24. Cazzulo, J.J. Aerobic fermentation of glucose by trypanosomatids. FASEB J. 1992, 6, 3153-3161. [CrossRef] [PubMed]

25. Opperdoes, F.R.; Michels, P.A. Enzymes of carbohydrate metabolism as potential drug targets. Int. J. Parasitol. 2001, 31, 482-490. [CrossRef]

26. Cruz-Saavedra, L.; Vallejo, G.A.; Guhl, F.; Messenger, L.A.; Ramírez, J.D. Transcriptional remodeling during metacyclogenesis in Trypanosoma cruzi I. Virulence 2020, 11, 969-980. [CrossRef] [PubMed]

27. Shah-Simpson, S.; Lentini, G.; Dumoulin, P.C.; Burleigh, B.A. Modulation of host central carbon metabolism and in situ glucose uptake by intracellular Trypanosoma cruzi amastigotes. PLoS Pathog. 2017, 13, e1006747. [CrossRef] [PubMed]

28. Shiratsubaki, I.S.; Fang, X.; Souza, R.O.O.; Palsson, B.O.; Silber, A.M.; Siqueira-Neto, J.L. Genome-scale metabolic models highlight stage-specific differences in essential metabolic pathways in Trypanosoma cruzi. PLoS Negl. Trop. Dis. 2020, 14, e0008728. [CrossRef] [PubMed]

29. Parsons, M. Glycosomes: Parasites and the divergence of peroxisomal purpose. Mol. Microbiol. 2004, 53, 717-724. [CrossRef]

30. Michels, P.A.M.; Villafraz, O.; Pineda, E.; Alencar, M.B.; Cáceres, A.J.; Silber, A.M.; Bringaud, F. Carbohydrate metabolism in trypanosomatids: New insights revealing novel complexity, diversity, and species-unique features. Exp. Parasitol. 2021, 224, 108102. [CrossRef]

31. Shah-Simpson, S.; Pereira, C.F.; Dumoulin, P.C.; Caradonna, K.L.; Burleigh, B.A. Bioenergetic profiling of Trypano soma cruzi life stages using Seahorse extracellular flux technology. Mol. Biochem. Parasitol. 2016, 208, 91-95. [CrossRef] [PubMed]

32. Avila, A.R.; Dallagiovanna, B.; Yamada-Ogatta, S.F.; Monteiro-Góes, V.; Fragoso, S.P.; Krieger, M.A.; Goldenberg, S. Stage-specific gene expression during Trypanosoma cruzi metacyclogenesis. Genet. Mol. Res. 2003, 2, 159-168.

33. Paes, M.C.; Saraiva, F.M.S.; Nogueira, N.P.; Vieira, C.S.D.; Dias, F.A.; Rossini, A.; Coelho, V.L.; Pane, A.; Sang, F.; Alcocer, M. Gene expression profiling of Trypanosoma cruzi in the presence of heme points to glycosomal metabo lic adaptation of epimastigotes inside the vector. PLoS Negl. Trop. Dis. 2020, 14, e0007945. [CrossRef] [PubMed]

34. Barisón, M.J.; Rapado, L.N.; Merino, E.F.; Furusho Pral, E.M.; Mantilla, B.S.; Marchese, L.; Nowicki, C.; Silber, A.M.; Cassera, M.B. Metabolomic profiling reveals a finely tuned, starvation-induced metabolic switch in Trypanosoma cruzi epimastigotes. J Biol. Chem. 2017, 292, 8964-8977. [CrossRef] [PubMed]

35. Ibáñez, A.B.; Bauer, S. Analytical method for the determination of organic acids in dilute acid pretreated biomass hydrolysate by liquid chromatography-time-of-flight mass spectrometry. Biotechnol. Biofuels 2014, 7, 145. [CrossRef]

36. Masson, S.; Sciaky, M.; Desmoulin, F.; Fontanara, E.; Cozzone, P.J. Simple cation-exchange high-performance liquid chromatography optimized to measure of metabolites in the effluents from perfused rat livers using refrac tive index and ultraviolet detectors. J. Chromatogr. 1991, 563, 231-242. [CrossRef]

37. Toyoka, T. Use of derivation to improve the chromatographic properties and detection selectivity of physiologically important carboxylic acids. J. Chromatogr. B 1995, 671, 91-112. [CrossRef]

38. Ding, M.; Chen, P.; Luo, G. High performance liquid chromatographic analysis of organic acids in foods. Chin. J. Chromatogr. 1997, 15, 212-215.

39. Cazzulo, J.J.; Franke, M.C.C.; Cazzulo, B.M.F. On the regulatory properties of the pyruvate kinase from Trypanosoma cruzi epimastigotes. FEMS Microbiol. Lett. 1989, 59, 259-263. [CrossRef] 
40. Schaub, G.A. An update on the knowledge of parasite-vector interactions of Chagas Disease. Res. Rep. Trop. Med. 2021, 12, 63-76. [CrossRef]

41. Urbina, J.A. Intermediary metabolism of Trypanosoma cruzi. Parasitol. Today 1994, 10, 107-110. [CrossRef]

42. Sant'Anna, C.; de Souza, W.; Cunha-e-Silva, N. Biogenesis of the reservosomes of Trypanosoma cruzi. Microsc. Microanal. 2004, 10, 637-646. [CrossRef] [PubMed]

43. Figueiredo, R.C.Q.; Steindel, M.; Soares, M.J. The reservosomes of epimastigotes forms of Trypanosoma cruzi: Occurrence during in vitro cultivation. Parasitol. Res. 1994, 80, 517-522. [CrossRef] [PubMed]

44. Sant'Anna, C.; Nakayasu, E.S.; Pereira, M.G.; Lourenço, D.; De Souza, W. Subcellular proteomics of Trypanosoma cruzi reservosomes. Proteomics 2009, 9, 1782-1794. [CrossRef]

45. Rogerson, G.W.; Gutteridge, W.E. Catabolic metabolism in Trypanosoma cruzi. Int. J. Parasitol. 1980, 10, 31-35. [CrossRef]

46. Engel, J.C.; Franke de Cazzulo, B.M.; Stoppani, A.O.; Cannata, J.J.; Cazzulo, J.J. Aerobic glucose fermentation by Trypanosoma cruzi axenic culture amastigote-like forms during growth and differentiation to epimastigotes. Mol. Biochem. Parasitol. 1987, 26, 1-10. [CrossRef]

47. Wood, D.E.; Schiller, E.L. Trypanosoma cruzi: Comparative fatty acid metabolism of the epimastigotes and trypomastigotes in vitro. Exp Parasitol. 1975, 38, 202-207. [CrossRef]

48. Souza, R.O.O.; Damasceno, F.S.; Marsiccobetre, S.; Biran, M.; Murata, G.; Curi, R.; Bringaud, F.; Silber, A.M. Fatty acid oxidation participates in resistance to nutrient-depleted environments in the insect stages of Trypanosoma cruzi. PLoS Pathog. 2021, 17, e1009. [CrossRef]

49. Guarneri, A.A.; Schaub, G.A. Interaction of triatomines, trypanosomes, and microbiota. In Triatominae-The Biology of Chagas Disease Vectors; Guarneri, A.A., Lorenzo, M.G., Eds.; Springer Nature: New York, NY, USA, 2021; pp. 345-386.

50. Pereira, M.G.; Nakayasu, E.S.; Sant'Anna, C.; De Cicco, N.N.; Atella, G.C.; de Souza, W.; Almeida, I.C.; Cunha-e-Silva, N. Trypanosoma cruzi epimastigotes are able to store and mobilize high amounts of cholesterol in reservosome lipid inclusions. PLoS ONE 2011, 6, e22359. [CrossRef]

51. Cruz-Saavedra, L.; Vallejo, G.A.; Guhl, F.; Ramírez, J.D. Transcriptomic changes across the life cycle of Trypanosoma cruzi II. Peer J. 2020, 8, e8947. [CrossRef]

52. Denicola-Seoane, A.; Rubbo, H.; Prodanov, E.; Turrens, J.F. Succinate-depende metabolism in Trypanosoma cruzi epimastigotes. Mol. Biochem. Parasitol. 1992, 54, 43-50. [CrossRef]

53. Contreras, V.T.; De Lima, A.R.; Zorrilla, G. Trypanosoma cruzi: Maintenance in culture modify gene and antigenic expression of metacyclic trypomastigotes. Mem. Inst. Oswaldo Cruz 1998, 93, 753-760. [CrossRef] [PubMed] 